\title{
Sergio Giraldo y El Informalismo Matérico:
}

El informalismo es la corriente que Sergio asume para la búsqueda de su memoria y las sensaciones de su infancia. En su exploración en el taller con diferentes sustancias no pictóricas como brea, cemento, fique, tela, etc. y elementos encontrados ha llegado a una línea de lo informal con énfasis en la materia, dando más importancia a la impresión que estos elementos puedan transmitir que a la misma forma. Estos elementos heterogéneos son aplicados en la mayoría de las veces con la mano, haciendo raspaduras, grietas, veladuras y rasgados a la superficie. En ocasiones el fuego y el ácido también juegan un papel importante para lograr que de esas superficies llenas de texturas emerjan objetos y sensaciones ocultas que conducen a un universo poético.

\section{Sergio Giraldo Giraldo}

serarteg@yahoo.com

www.sergiogiraldo.com

\section{Estudios}

Fellow Yamagata, The Corcoran School of Arts, Washington D.C. U.S.A.

\section{Exposiciones Individuales}

- Sala de Exposiciones, Casa Municipal de la Cultura, Caldas-Antioquia, 1995.

- Sala Fundadores, Universidad EAFIT, Medellín, 1997.

- Sala Comfenalco "La Playa", Medellín, 2002.

- Congreso de la República de Colombia, Bogotá D.C., 2007.

- Parque Biblioteca Belén, Medellin 2010.

- Galería Trementina, Bogotá D.C., 2011.

\section{Exposiciones Colectivas}

2005

- Connections 2, Carrier Gallery, Toronto, Canadá.

2007

- XII Salón Regional de Artistas, Alianza Cultural Colombo-Francesa, Pereira.

- XII Salón Regional de Artistas, Museo de Arte Moderno de Medellín.
2008

- 41 Salón Nacional de Artistas, CaliColombia.

- Arte en la vía - Arte Público, Medellín, Colombia.

2009

- Sueños NoMinados, Gobernación de Cundinamarca, Bogotá-Colombia.

2010

- Sueños NoMinados, Centro Cultural Pensart, Bogotá-Colombia.

- Art Ability, Philadelphia U.S.A.

- Revealing Culture, John F. Kennedy Center for the Performing Arts, Washington, D.C.

- "Doce Años de Rehabilitación con Arte" Fundación Miguel Ángel Garcés Montoya, Medellín.

- XVI Bienal Nacional de Artes para personas con discapacidad, Sala Suramericana, Medellín.

\section{1}

- Galería Bryn Mawr, Malven U.S.A.

\section{Reconocimientos}

- Representar a Colombia en el International Visual Arts Institute, USA 1997.

- Mención en el IX Salón Nacional de Artistas Universidad de Antioquia, Medellín 1998.
- Premio XII Salón Nacional de Arte para personas con discapacidad, Medellín 2001.

- Mención en el X Salón Regional de Artistas, zona Antioquia, 2003.

- Representar a Colombia en el International VSA arts Festival, Washington D.C. 2004.

- Premio The Pollock-Krasner Foundation, Inc., New York 2005.

- Premio The Pollock-Krasner Foundation, Inc., New York 2006.

- Revista Alemana Behinderung und Dritte Welt, for Disability and International Development, 2008.

- Premio Arte Público, Secretaria de Tránsito y Museo de Antioquia, 2008.

- Beca de creación en Artes Visuales, Medellín 2009.

- Mención como Artista Nacional Destacado en situación de Discapacidad, Colombia 2009.

- Premio Art Ability, Philadelphia 2009. 